DOI 10.37882/2223-2974.2021.03.28

\title{
ПРОБЛЕМЫ ПРАВОВОЙ ОХРАНЫ ИСКУССТВЕННОГО ИНТЕЛЛЕКТА В ОБЛАСТИ ИНТЕЛЛЕКТУАЛЬНОЙ СОБСТВЕННОСТИ
}

\section{PROBLEMS OF LEGAL PROTECTION OF ARTIFICIAL INTELLIGENCE IN THE FIELD OF INTELLECTUAL PROPERTY}

\section{A. Sergeev}

Summary: Global innovative technological processes in the world open up new horizons for research by legal scholars. In the article, the author raises questions of the legal personality of artificial intelligence, its place in civil law relations. The complexity and relevance of the topic make it possible to form bold ideas that in the future can be put into the development of a block of new laws and regulations concerning all areas of artificial intelligence participation in human life. The article deals with legal aspects, raises philosophical questions. As a result, the author gives examples of amendments that can become the first step towards the formation of a new branch of law.

Keywords: artificial intelligence, copyright, legal personality, responsibility, program.
$\mathrm{H}$ аучные и технологические достижения прошлого и нынешнего столетия открывают перед всем человечеством большие перспективы. Инновационные достижения в области нейросетей и искусственного интеллекта выводят на новый уровень многие привычные для нас сферы жизни. И, как правило, за разработками ученых не успевает правовая отрасль, которая не может своевременно дать юридическую и этическую оценку новым явлениям. Да и стоит ли спешить с выводами, когда речь идет о фундаментальных вопросах, которые поднимаются в этой статье?

Само понятие искусственный интеллект имеет широкую трактовку, и нет единого мнения среди ученых (не только правоведов), что именно стоит подразумевать, когда обращаешься к этому термину. В первую очередь следует понимать, что мы говорим о совокупности дисциплин в области программирования, логики, системы обучения, исчисления и даже философии и психологии. Термин был предложен в 1956 году Джоном Маккарти: «Это наука и технология создания интеллектуальных машин, в особенности - интеллектуальных компьютерных программ. Искусственный интеллект связан с задачей использования компьютеров для понимания работы человеческого интеллекта, но не ограничивается использованием методов, наблюдаемых в биологии» [1]. Сам искусственный интеллект стоит подразумевать как
Сергеев Алексей Валерьевич

Преподаватель, МФПА «Синергия»

sergeev1597@mail.ru

Аннотация: Глобальные инновационные технологические процессы в мире открывают новые горизонты для исследования учеными-правоведами. В статье автор поднимает вопросы правосубъектности искусственного интеллекта, его места в гражданско-правовых отношениях. Сложность и актуальность темы позволяют формировать смелые идеи, которые в будущем могут быть положены в разработку блока новых законов и норм, касающихся всех сфер участия искусственного интеллекта в жизни людей. В статье рассматриваются юридические аспекты, поднимаются философские вопросы. В результате автор приводит примеры поправок, которые могут стать первым шагом на пути к формированию новой отрасли права.

Ключевые слова: искусственный интеллект, авторское право, правосубъектность, ответственность, программа.

конечный результат, в который вложен труд создателей. Обобщая все научные определения, можно выразить, что искусственный интеллект, ИИ, artificial intelligence, $\mathrm{Al}$ - это программная система, написанная на языке программирования, которая может быть реализована и запущена на отдельном компьютере, машине, роботе или другом техническом оборудовании, имеющим адаптивный для использования интерфейс и софт-оснащение, и способна воспроизводить когнитивные и сознательные функции человеческого мозга. Выделяют также отдельную область науки с аналогичным термином.

В российских нормативных актах мы можем найти следующее определение: «Искусственный интеллект комплекс технологических решений, позволяющий имитировать когнитивные функции человека (включая самообучение и поиск решений без заранее заданного алгоритма) и получать при выполнении конкретных задач результаты, сопоставимые, как минимум, с результатами интеллектуальной деятельности человека» [10].

Цели создания могут быть самые разные, но ключевым моментом служит тот факт, что ИИ наделяется свойствами выполнять функции, которые ранее могли быть выполнены исключительно человеком или иным биологическим существом, обладающим сознанием и способностью анализировать. ИИ умеет распознавать 
голос, внешность, реальность, ведет конструктивный и осознанный диалог. В рамках данной статьи мы также обращаемся к главным возможностям искусственного интеллекта, к его умению создавать уникальные произведения искусства, живописи, литературные и музыкальные произведения.

ИИ помогает человечеству достигать определенных целей, например, авиалюбители используют приложение «Flightradar24», для того чтобы отследить тысячи самолетов по всему миру или посмотреть загруженность авиатрассы возле своего дома. Если посмотреть за кулисы этого приложения, то мы увидим, что тысячи самолетов ежесекундно передают данные о состоянии самолета. Именно поэтому приложение знает о том, в каком состоянии находится каждый самолет, какая его скорость, высота и многое другое. А что, если миллионы людей будут передавать информацию о себе, своих политических предпочтениях, состоянии здоровья и тому подобном в какое-нибудь приложение типа «Политическое предпочтение РФ». И этот алгоритм, учитывая статистические данные, будет, например, направлять финансы на поддержку здравоохранения в одном регионе, на развитие образования в другом. Тогда мы все будем находиться в прямой зависимости от искусственного интеллекта. Это звучит на гране фантастики, но к этому мы все ближе и ближе. Посмотрите на эти приложения: Apple c «Siri» и Яндекс с «Алисой». Такой скачок в научном прогрессе порождает множество вопросов. Можно ли считать искусственный интеллект объектом или субъектом авторского права? А если искусственный интеллект, управляющий самолетом, приведет к цепочке необратимых действий, и в результате все пассажиры погибнут. Возможно ли будет обратиться в суд с требованиями для возмещения вреда не с авиакомпании, а с искусственного интеллекта? Мы попробуем ответить на данные вопросы с учетом мнения учёных, при помощи исследования международного и внутреннего законодательства.

Перед обществом встает вопрос, сможет ли искусственный интеллект превзойти человека, где его место и каков статус в гражданско-правовых отношениях. Хамитов Н.В., Киселица С.В., Деркач О.Л. ставят вопрос о телесности носителя искусственного интеллекта и пишут: «Учитывая, что телесность есть физическая составляющая субъекта ИИ, возникает вопрос о физической картине этого субъекта. На начальном этапе речь идет о физической картине мира, закладываемой в модель искусственного интеллекта его авторами. Полагаем, что на начальном этапе достаточно принять классическую картину мира» [6].

Мы видим успешные проекты, которые запускают сегодня разработчики. Активно используется ИИ в банковской сфере, сфере страхования, в биржевой торговле.
Биолог Александр Панчин взял интервью у GPT-3, где ИИ назвал своими врагами природу, энтропию и смерть. Отсюда встает вполне оправданный вопрос, достаточно ли у человечества ресурсов противостоять ИИ в том случае, если его самосознание превзойдет уровень самосознания людей, открывая безграничные и ничем не контролируемые способности влиять на все процессы в мире. Искусственный интеллект учится точно также как и мы, только в больших масштабах.

Особенно актуальны вопросы защиты авторских прав при участии в создании ИИ. Задача ученых теоретиков и правоведов сформировать обоснованную позицию в отношении корреляции понятий права авторства и искусственного интеллекта. Пункт 1 статьи 1228 Гражданского кодекса Российской Федерации (далее - ГК РФ) утверждает, что автором может быть только физическое лицо. Если анализировать эту статью, можно прийти к выводу, что не может быть признано автором произведения лицо, разработавшее ИИ, который создал это произведение.

Как отмечает издание РБК, в законодательстве ряда стран (Великобритания, Новая Зеландия) уже давно действуют нормы, распространяющие авторско-правовую охрану на произведения, созданные компьютером. Автором считается лицо, создавшее необходимые условия для создания произведения. Это может быть как программист, так и пользователь [7].

Вопрос о том, какой правовой статус следует распространять на искусственный интеллект, довольно актуален. Минченков Е.Н. считает преждевременным наделять ИИ авторскими правами: «Считаем обоснованным в таком случае подход, в котором автором и правообладателем, соответственно, будет признаваться владелец (собственник) робота» [9]. Также встаёт ещё вопрос и о праве собственности на вещи. Мы понимаем, что понятие вещей первой необходимости для человека и ИИ совершенно разные. ИИ необходимо электропитание, набор программ и софта для обеспечения безопасности, исправно работающие комплектующие носителя, сервер для хранения баз данных и файлов с кодом. Вопрос деликтоспособности и участия в трудовых отношениях также поднимается сегодня правоведами [8]. Васильев А.А., Печатнова Ю.В. справедливо утверждают, что в целях оптимального правового регулирования использования искусственного интеллекта разработчики, исследователи и лица, финансирующие исследования в сфере искусственного интеллекта, а также в смежных областях, должны исходить из презумпции опасности искусственного интеллекта, подразумевая, что созданная или создаваемая технология искусственного интеллекта является опасной для человека, пока не доказано иного [11].

В соответствии с законодательством и прецедентной практикой ЕС произведение считается оригинальным, 
если оно отражает «собственное интеллектуальное творчество автора», т.е. выражение личного прикосновения автора и результат свободного творческого выбора [2]. И законы ЕС, и США устанавливают, что работа должна быть непосредственным (прямым) причинным результатом действий человека. Это означает, что ИИ в настоящее время понимают как интеллект, полностью реализованный с помощью вычислительных средств, который не может самостоятельно делать свободный и творческий выбор, и что концепция творчества неприменима к машинам [5].

Неминуемо встаёт вопрос о том, а каков будет правовой статус искусственного интеллекта после смерти его владельца? Кто будет нести ответственность за все то, что успеет совершить ИИ? Вопрос об ответственности поднимался в Резолюции Европарламента от 16 февраля 2017 года. В документе указывается, что искусственный интеллект не может нести ответственность сам по себе, поскольку его действия или бездействия зависят от оператора (владельца). Но этот вопрос открыт для обсуждения. И в случае сильно развитого ИИ, законодатель обязан пересмотреть пределы ответственности самого интеллекта, его оператора или создателя.
В российское право стоит внести ряд поправок, закрепляющих статус искусственного интеллекта. Первым шагом могут стать поправки в ГК РФ:

- статью 128 после слова «индивидуализации» дополнить словами «и результаты, созданные системой искусственного интеллекта».

Далее стоит внести отдельную Главу в подраздел Лица в ГК РФ, где будет закреплен статус искусственного интеллекта.

Резюмируя вышеизложенное, стоит поднимать вопросы правового статуса искусственного интеллекта не только на внутригосударственном уровне, но и на международном. Уже сейчас ученые прогнозируют скачок в развитии ИИ в глобальном масштабе. К обсуждению поднятой темы необходимо привлекать комиссию из выдающихся ученых: правоведов, биологов, химиков, физиков, программистов, философов. Будут подниматься вопросы деликтоспособности, правосубъектности, возможности участия в трудовых, семейных и иных правоотношениях на паритетных с человеком началах и многие другие нерешенные задачи.

\section{ЛИТЕРАТУРА}

1. НABR / 1cloud.ru. Искусственный интеллект: что о нем думают ученые // [Электронный ресурс] режим доступа: URL https://habr.com/ru/company/1cloud/ blog/281282/ (дата обращения: 07.02.2021).

2. Директива Совета Европы 2009/24 / ЕС // [Электронный ресурс] режим доступа: URL https://eur-lex.europa.eu/LexUriServ/LexUriServ.do?uri=0J:L:2009:111: 0016:0022:EN:PDF (дата обращения: 07.02.2021).

3. Директива Европейского Парламента «0 правовой защите баз данных» 96/9 / EC // [Электронный ресурс] режим доступа: URL https://eur-lex.europa.eu/ legal-content/EN/TXT/HTML/?uri=CELEX:31996L0009\&from=EN (дата обращения: 07.02.2021).

4. Директива 2001/29 / ЕС Европейского парламента и Совета от 22 мая 2001 г. «0 гармонизации некоторых аспектов авторского права и смежных прав в информационном обществе» // [Электронный ресурс] режим доступа: URL https://eur-lex.europa.eu/LexUriServ/LexUriServ. do?uri=CELEX:32001L0029:EN:HTML (дата обращения: 07.02.2021).

5. CreativeCommons.org / Brigitte Vézina, Brent Moran. 2020Искусственный интеллект и творчество: почему мы против защиты авторских прав на результаты, созданные с помощью ИИ // [Электронный ресурс] режим доступа: URL https://creativecommons.org/2020/08/10/no-copyright-protection-for-aigenerated-output/ (дата обращения: 07.02.2021).

6. Хамитов Н.В., Киселица С.В., Деркач 0.Л. Проблема телесности субъекта искусственного интеллекта в контексте теории эволюции естественного и искусственного интеллекта // Проблеми соціальної роботи: філософія, психологія, соціологія. 2017. № 2 (10). С. 95-102.

7. РБК/ Пчелкин. А. / Авторские правки: кому принадлежат права на творчество ИИ // [Электронный ресурс] режим доступа: URL https://trends.rbc.ru/ trends/industry/5e00b2ef9a794763f8a7b105 (дата обращения: 07.02.2021).

8. Маннова А.А., Рожкова В.Р. Искусственный интеллект как субъект трудового права // В сборнике: Актуальные вопросы публичного права. Сборник трудов конференции XVIII Всероссийской научной конференции молодых ученых и студентов. 2019. С. 518-522.

9. Минченков Е.Н. Робот-автор: к вопросу о возможности наделения юнитов искусственного интеллекта авторскими правами // В сборнике: Теория и практика современной юридической науки. Материалы VII всероссийской научно-практической конференции. Отв. редактор Е.Б. Гоголевская. Науч. редактор И.С. Кокорин. 2020. С. 230-236.

10. О развитии искусственного интеллекта в Российской Федерации: указ Президента Российской Федерации от 10.10.2019 №490. URL: http://www.kremlin. ru/acts/bank/44731/page/1 (дата обращения: 02.08.2021).

11. Васильев А.А., Печатнова Ю.В. Искусственный интеллект и право: проблемы, перспективы // Российско-азиатский правовой журнал. 2020. № 2. С. 14-18.

○ Сергеев Алексей Валерьевич (sergeev1597@mail.ru). 